\title{
Mass transfer efficiency of a vacuum airlift - Application to water recycling in aquaculture systems
}

\author{
Bertrand Barrut $^{\mathrm{a}}$, Jean-Paul Blancheton ${ }^{\mathrm{b}, *}$, \\ Jean-Yves Champagne ${ }^{c}$, Alain Grasmick $^{d}$
}

\footnotetext{
a ARDA, Station Marine du Port, Port Ouest, Hangar 10, 97420 Le Port, Reunion Island (France)

b IFREMER, Station d'Aquaculture Expérimentale, Laboratoire de Recherche Piscicole de Méditerranée. Chemin de Maguelone, 34250 Palavas-les-Flots, France

c LMFA, UMR CNRS 5509, Université de Lyon, Ecole Centrale de Lyon, Université Lyon 1, INSA de Lyon, ECL, 20, avenue Albert Einstein - 69621, Villeurbanne Cedex, France

d Institut Européen des Membranes (UMR-CNRS 5635), Université Montpellier II, CC005, Place Eugène Bataillon, 34095 Montpellier Cedex 05, France
}

* Corresponding author. Tel.: +33 4671304 12; fax: +33 4671304 58. E-mail address: Jean.Paul.Blancheton@ifremer.fr (J.-P. Blancheton).

\begin{abstract}
:
In aquaculture, oxygen transfer and carbon dioxide stripping are the first limiting factors to fish rearing intensification. In this study we measured the $\mathrm{O}_{2}$ and $\mathrm{CO}_{2}$ mass transfer coefficient $\left(\mathrm{K}_{\mathrm{L}} \mathrm{a}\right)$ for a vacuum airlift in fresh (<1 \%o salinity) and sea water (35\%o salinity) Recirculating Aquaculture Systems (RAS). The airlift was composed of two concentric tubes: an inner riser tube and an external downcomer tube and can be adjusted at three different heights: 2, 4 or $6 \mathrm{~m}$. Several types of air injectors were tested, delivering different sizes of bubble swarms depending on their porosity and functioning conditions (low or high injection pressure), with air flows varying from 0 to $80 \mathrm{~L} \mathrm{~min}^{-1}$. Experiments were also carried out at different water circulation velocities and with cold $\left(7^{\circ} \mathrm{C}\right)$ and warm water $\left(22^{\circ} \mathrm{C}\right)$. The best transfer coefficient $\left(\mathrm{K}_{\mathrm{L}} \mathrm{a}\right)$ value was obtained at a high air flow rate, a high temperature and with reduced bubble size. Results showed that $\mathrm{K}_{\mathrm{L}} \mathrm{a}$ was not affected by water salinity, but it was slightly affected by water flow $\left(\mathrm{Q}_{w}\right)$, airlift inner pipe length and vacuum. The presence of vacuum reduces gas solubility in water and facilitates $\mathrm{CO}_{2}$ stripping. The comparison between $\mathrm{O}_{2}$ and $\mathrm{CO}_{2}$ transfers showed that higher $\mathrm{K}_{\mathrm{L}}$ a values were obtained for $\mathrm{O}_{2}$ than for $\mathrm{CO}_{2}$ in fresh and sea water, probably due to chemical reactions between the $\mathrm{CO}_{2}$ and water. For RAS, the vacuum airlift provides a Standard Aeration Efficiency (SAE) of $1.13 \mathrm{KgO}_{2} \mathrm{KW} \mathrm{h}^{-1}$ and a Standard Stripping Efficiency (SSE) of $1.8 \mathrm{KgO}_{2} \mathrm{KW} \mathrm{h}{ }^{-1}$ or $0.023 \mathrm{KgCO}_{2} \mathrm{KW} \mathrm{h}$. In rearing water, $\mathrm{CO}_{2}$ and $\mathrm{O}_{2}$ transfers were negatively affected when feed was added. An empirical model for $\mathrm{CO}_{2}$ mass transfer coefficient prediction was developed and calibrated. Simulation shows a good correlation between predicted and measured values $\left(R^{2}=0.87\right)$.
\end{abstract}

Keywords: Mass transfer ; Airlift ; Vacuum ; Aquaculture ; RAS ; Aeration ; Degasification ; Salinity 


\section{Introduction}

An airlift is obtained by introducing compressed gas (generally air) at the bottom of a pipe partially submerged in the liquid. It generates a vertical movement of the fluid (often water but sometimes a mixture of liquids and solids). The principle is that the presence of gas bubbles decreases the average gas-liquid density and creates the driving force of the pump (Awari et al., 2004). Airlift pumps are often used in difficult pumping operations such as deep-sea mineral mining, estuaries dredging, coal extracting or in oil, chemical or radiochemical industries, because they are reliable for lifting corrosive and/or toxic, explosive, volatile or viscous substances.

In recirculating aquaculture systems (RAS), water is usually circulated by pumps but airlifts are increasingly widely used (Mozes et al., 2004; Blancheton et al., 2007; Mamane et al., 2010). Airlifts are easy to build, simple to use and economical: Energy costs of airlift pumps for water transport and aeration are $35 \%$ lower compared to standard pumps when used with low head systems (Reinemann, 1987; Awari et al., 2004; Kassab et al., 2009; Roque d'Orbcastel et al., 2009). In addition, in spite of their $80 \%$ efficiency, pumps have a limited lifetime and require more maintenance than airlift pumps (Kassab et al., 2007). Moreover, airlifts can combine different functions such as water transport, aeration, $\mathrm{CO}_{2}$ stripping and foam fractionation in the same treatment device, which may decrease the occurrence of breakdown, reduce the need for technical supervision and space used (Roque d'Orbcastel et al., 2009; Barrut et al., 2011).

The main disadvantage of airlift pumping is the low water delivery height (i.e. lift height), limited to a maximum of around $0.3 \mathrm{~m}$, which, in case of clogging, could reduce water flow by partial obstruction. For acceptable water flow, head loss must be reduced in the water supply system and airlift must be designed with a large submergence ratio. The submergence ratio is defined as the average pressure gradient along the tube i.e. the ratio between the submergence (static height of water $(\mathrm{H})$ ) and the total length of the pipe (the sum of the static height of water $(\mathrm{H})$ and the lift height $(\mathrm{L})$ ). This ratio has to be set above 0.7 to obtain an efficiency comparable to other pump types (Kassab et al., 2007). When the submergence ratio is too small (low immersion or high lift), water flow is almost null and the working cost of the pump is high (Parker and Suttle, 1987; Loyless and Malone, 1998; Awari et al., 2004).

The design parameters of airlift water circulation systems must therefore be precisely defined (Kassab et al., 2007). The parameters of airlift pumps studied in the literature are rising tube diameter, water flow (or liquid circulation velocity), airflow (or superficial gas velocity) and submergence ratio (Nicklin, 1963; Parker and Suttle, 1987; Reinemann, 1987; Wurts et al., 1994). All these parameters directly affect airlift pump performance but few studies have been carried out on combined variations of these parameters, probably because of the large number of experiments required.

To determine the effects of water characteristics, Khalil et al. (1999) tested different types of fluids and showed that lower fluid surface tension could improve airlift pump efficiency by $30 \%$. However, they did not characterize the effect of salinity on water flow rate. As bubble size distribution has a significant effect on the efficiency of airlift pumps and is decisive for their functioning, special attention was paid to bubble size distribution, which depends on the type of diffusers and water characteristics (Barrut et al., 2011).

Several models were investigated based on empirical studies (Loyless and Malone, 1998; Awari et al., 2004), but the accuracy of their predictive value is still limited and varies according to the specific configuration of each system (geometry, type of air injector), to the characteristics of the liquids (Loyless and Malone, 1998) and depending on what the airlift pump is used for (Wurts et al., 1994). Although the geometry of the airlift pump seems to be simple, the theoretical study of its performance appears to be complicated (Kassab et al., 2009). The technology is still under development and will require intensive field testing before models can be predictive (Kassab et al., 2009).

The vacuum airlift technology consists in (1) a vertical tube at the top of which a controlled vacuum is created by a vacuum pump to keep the water level stable, and at the bottom of which gas is injected similarly to a standard airlift, and (2) a downcomer tube to drive the water back to the pumping tank. The vacuum reduces air injection energy costs while maintaining a significant part of the pipe length above water level, thereby increasing the submergence ratio without the need of deep zones in the pumping area (Fig. 1). In addition, the risk of gas oversaturation is avoided by low air injection depths (Loyless and Malone, 1998). Use of a vacuum also allows the gas injected or removed from the fluid to be collected, for storage before treatment in the case of off-gas. 
The aim of this study was to test the water transport capacity of a vacuum airlift with fresh water, sea water and fish rearing sea water. The specific objectives were to characterize the hydraulic capacity of a vacuum airlift and compare it to other pumping systems commonly used in RAS.

\section{Materials and methods}

\subsection{Experimental setup and parameters tested}

The experimental equipment used to study the transport function of the vacuum airlift pump is shown in Figure 1. It comprised a $1000 \mathrm{~L}$ tank (1) connected to a vacuum airlift provided by COLDEP ${ }^{\circledR}$ (2) composed of two concentric vertical transparent PVC pipes. The outer diameter (OD) of the internal pipe was $160 \mathrm{~mm}$. The diameter of the external pipe was $315 \mathrm{~mm}$ (OD) along the first meter and $250 \mathrm{~mm}(\mathrm{OD})$ after the first meter and up to the top (Fig. 1). The top of the vacuum airlift was hermetically closed and connected to a vacuum pump (3) (BUSCH - Mink MM.1100.BV) with a maximal airflow of $60 \mathrm{~m}^{3} \mathrm{~h}^{-1}$. The vacuum created by the pump allows water to rise in the internal pipe. A pressure gauge (4) ranging from -1 bar to 1 bar, connected to the frequency converter of the pump's electric motor, was used to control pressure level and regulate water height in the vacuum airlift. At the top of the vacuum airlift, the difference in height between the internal and external tubes was set at 0.2 $\mathrm{m}$, to limit head losses when water flow passed from the internal to the external tube.

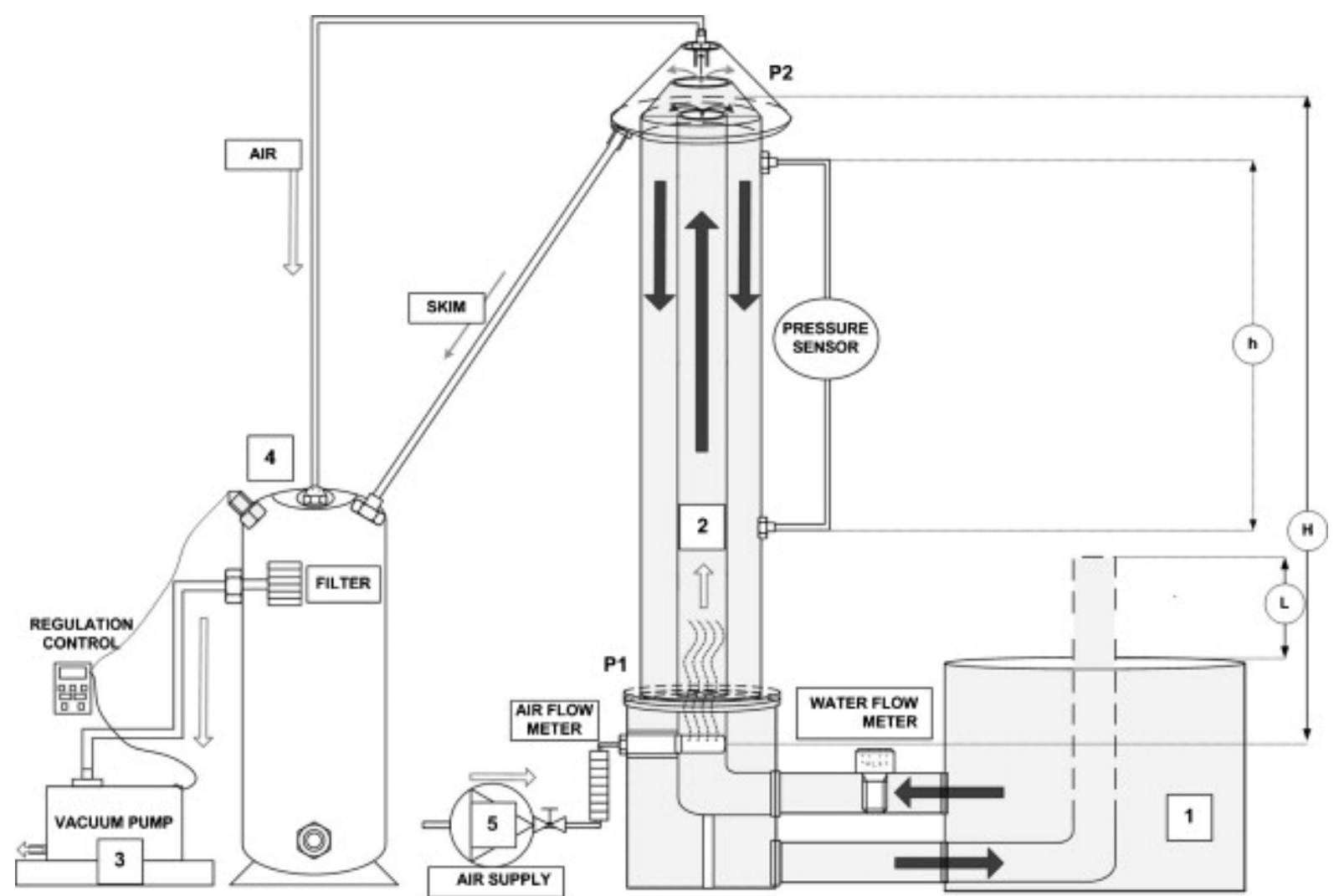

Fig. 1: Schematic diagram of the vacuum airlift set-up used for this study.

The positive role of injected air flow, bubble size and pipe length on airlift intensity in terms of pumping effect and conversely, the negative role of lift height have been extensively documented (Nicklin, 1963; Parker and Suttle, 1987; Loyless and Malone, 1998; Awari et al., 2004; Kassab et al., 2009; Moran, 2010b). Lift height (L) is defined as the distance from the water surface in the tank to the discharge pipe i.e. the outlet of the vacuum airlift (Fig. 1). A lift of $0.3 \mathrm{~m}$ is usually selected as the maximum height for airlift water delivery (Loyless and Malone, 1998; Moran, 2010b). 
The combination and the range of variations or values of each parameter tested to quantify water flow rate are given in Table 1.

\begin{tabular}{lllll}
\hline $\begin{array}{l}\text { Pipe length, } H \\
(\mathrm{~m})\end{array}$ & $\begin{array}{l}\text { Depression } \\
\text { (bar) }\end{array}$ & $\begin{array}{l}\text { Type of } \\
\text { injection }\end{array}$ & $\begin{array}{l}\text { Air flow } Q_{g} \\
\left(\mathrm{~L} \mathrm{~min}^{-1}\right)\end{array}$ & $\begin{array}{l}\text { Lift height, } L \\
(\mathrm{~m})\end{array}$ \\
\hline 6 & -0.5 & Micro bubble & $0-80$ & $0-0.3$ \\
6 & -0.5 & Fine bubble & $0-80$ & $0-0.3$ \\
6 & -0.5 & Open tube & $0-80$ & $0-0.3$ \\
4 & -0.3 & Fine bubble & $0-80$ & $0-0.3$ \\
2 & -0.15 & Fine bubble & $0-80$ & $0-0.3$ \\
\hline
\end{tabular}

Table 1 : Combination of all parameters tested to quantify water flow rate of the vacuum airlift.

Air was injected close to the bottom of the inner tube using an electric compressor (5) (BECKER DT4.40K), which delivers a maximum of $40 \mathrm{~m}^{3} \mathrm{~h}^{-1}$ at a pressure of 1 bar. Different types of injectors were used for air injection: an open tube diffuser which creates a swarm of large bubbles ( $>3 \mathrm{~mm})$, an injector working at a pressure of 0.5 bar which creates fine bubbles $(1 \mathrm{~mm})$ and an injector working at a pressure of 1 bar which creates microbubbles $(<1 \mathrm{~mm})$.

The pressure of injected air was controlled by a pressure gauge and airflow was measured using a rotameter (Key Instrument MR 3000 Series Flowmeter $\pm 5 \mathrm{~L} \mathrm{~min}^{-1}$ ). The water flow rate was measured using an electromagnetic flow meter Bürkert $\left( \pm 0.01 \mathrm{~m}^{3} \mathrm{~h}^{-1}\right)$ positioned at the inlet of the vacuum airlift.

Static pressure was measured at different heights in the inner tube by a pressure sensor (Rosemount) ( $\pm 1 \mathrm{mbar}$ ) and gas holdup $\left(\varepsilon_{\mathrm{g}}\right)$ in the inner tube, i.e. the volume fraction of gas in the gasliquid dispersion, was calculated using pressure drop as defined by Yu et al. (2008) in Eq. (1):

$\varepsilon_{g}=1-\frac{\Delta P}{\rho g h}$

where $\varepsilon_{g}$ is the gas holdup, $\Delta \mathrm{P}$ is the pressure drop between the two tapping ports $\left(\mathrm{N} \mathrm{m}^{-2}\right), \mathrm{h}$ is the vertical distance between the two tapping ports in the relevant measurement zone $(\mathrm{m}), \rho$ is the density of the liquid phase $\left(\mathrm{kg} \mathrm{m}^{-3}\right)$ and $\mathrm{g}$ is the gravitational acceleration $\left(\mathrm{m} \mathrm{s}^{-2}\right)$. This relation shows the link between gas holdup and density of the gas/liquid mixture in the riser tube. Associated with up-flow gas velocity, it constitutes the driving force of the airlift and corresponds to the instantaneous shifted water volume in the inner tube due to the air rising. Gas holdup thus appears to be a determining criterion correlated to both airflow and bubble size: for a given bubble size, an increase in airflow leads to an increase in gas holdup and consequently, to an increase in the pumping of water, whereas for a given air flow rate, a decrease in bubble diameter results in an increase in gas holdup, but a decrease in water flow rate due to decreased bubble rising velocity.

\subsection{Method for assessing water delivery and pumping efficiency}

For each experiment, gas holdup values, bubble diameters (when possible) and water flow intensity were measured. All measures involved fresh and sea water. Pumping efficiency ( $\eta$ ) was defined by Nicklin (1963) as the work done in lifting the liquid divided by the work done by the air as it expands isothermally. It was calculated using Eq. (2): 


$$
\eta=\frac{\rho g Q_{w} L}{p_{2} Q_{g} \ln \frac{p_{1}}{p_{2}}}
$$

where $\eta$ is the pumping efficiency, $Q_{w}$ is the water flow $\left(m^{3} s^{-1}\right), L$ is the lift height $(m), p_{1}$ is the injection pressure of air $\left(\mathrm{N} \mathrm{m}^{-2}\right), \mathrm{p}_{2}$ is the pressure at the tube top $\left(\mathrm{N} \mathrm{m}^{-2}\right), \mathrm{Q}_{\mathrm{g}}$ is the air flow $\left(\mathrm{m}^{3} \mathrm{~s}^{-1}\right)$. The calculated values obtained using our experimental conditions were compared to data in the literature.

\subsection{Method to evaluate the effect of vacuum on airlift pumping}

Since the negative pressure level in the vacuum airlift is dependent on pipe length, it is not possible to assess the effect of vacuum on gas holdup and air flow rate without varying the pipe length of the vacuum airlift. Therefore, a specific airlift was set up using a vertical transparent PVC tube of $160 \mathrm{~mm}$ (OD) and $2 \mathrm{~m}$ in length. At the bottom, air was injected with a fine bubble air injector. A pressure sensor was connected at different levels: $0.15 \mathrm{~m}, 0.4 \mathrm{~m}, 0.9 \mathrm{~m}$ and $1.5 \mathrm{~m}$. All measures were performed with or without vacuum at the top of the airlift and with different types of water (fresh or sea water). To measure the effect of the vacuum on air flow rate and gas holdup, air flow rate was set at $20 \mathrm{~L} \mathrm{~min}{ }^{-1}$ under atmospheric pressure. All measurements were carried out with the same analysis devices as described in section (2.1).

\subsection{Method to evaluate vacuum airlift performances in rearing conditions}

To study the hydraulic modification in fish rearing conditions, the vacuum airlift was connected to a $15 \mathrm{~m}^{3}$ rearing tank operated with an hourly water renewal rate of $100 \%$. The vacuum airlift and all the analysis devices were the same as described previously (sections 2.1). The livestock consisted of 200 $\mathrm{Kg}$ of red drums (Sciaenops ocellata) with an average weight of $15 \mathrm{~g}$. Feed consisted of fish pellets with a diameter of $2 \mathrm{~mm}$ (LE GOUESSANT - OMBRINE GROWER EXT-coul 2, $47 \%$ protein and 13 $\%$ lipids) and the daily feeding rate was $5 \%$ of total biomass. Water flow was measured every 10 to 30 minutes when testing the effect of feeding on airlift functioning.

\section{Results and discussion}

\subsection{Effect of air flow rate and air injector type on water flow}

With fresh water, when the air flow rate was too low $\left(0\right.$ to $\left.5 \mathrm{~L} \mathrm{~min}^{-1}\right)$, no water was lifted because the buoyant force exerted by the air bubbles was not sufficient to induce water rising (Awari et al., 2004, Kassab et al., 2009) (Fig. 2a). At higher air flow rates, the water flow delivered by the airlift pump increased with increasing airflow rates as follows:

- when the air flow rate increased from 0 to $20 \mathrm{~L} \mathrm{~min}^{-1}$, a rapid increase of water flow from 0 to 20

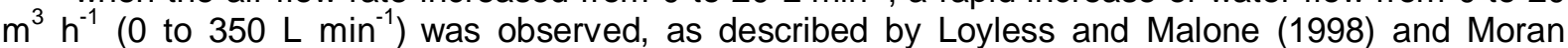
(2010b). In the range of 5 to $15 \mathrm{~L} \mathrm{~min}^{-1}$ of air injected, fluid transport progressed from a bubble flow to a slug flow in which the pipe cross section is filled alternatively with gas and liquid and which largely increased the transport capacity of the vacuum airlift irrespective of the type of air injector used (Nicklin, 1963; Kassab et al., 2009)

- from $20 \mathrm{~L} \mathrm{~min}^{-1}$ to $80 \mathrm{~L} \mathrm{~min}{ }^{-1}$ of air injected, water flow increased more slowly with airflow, up to 30 to $35 \mathrm{~m}^{3} \mathrm{~h}^{-1}$ (500 to $600 \mathrm{~L} \mathrm{~min}^{-1}$ ). In our study, the capacity of the compressor was not sufficient to reach maximum water flow. Reinemann et al. (1990), Awari et al. (2004) and Kassab et al. (2009) showed that when air flow is further increased, a maximum water flow rate is reached when the frictional pressure and head loss drop caused by additional air and vacuum airlift geometry exceed the buoyancy effect of the additional air. 
a Micro bubble SW

$\Delta$ Fine bubble SW

Open tube SW
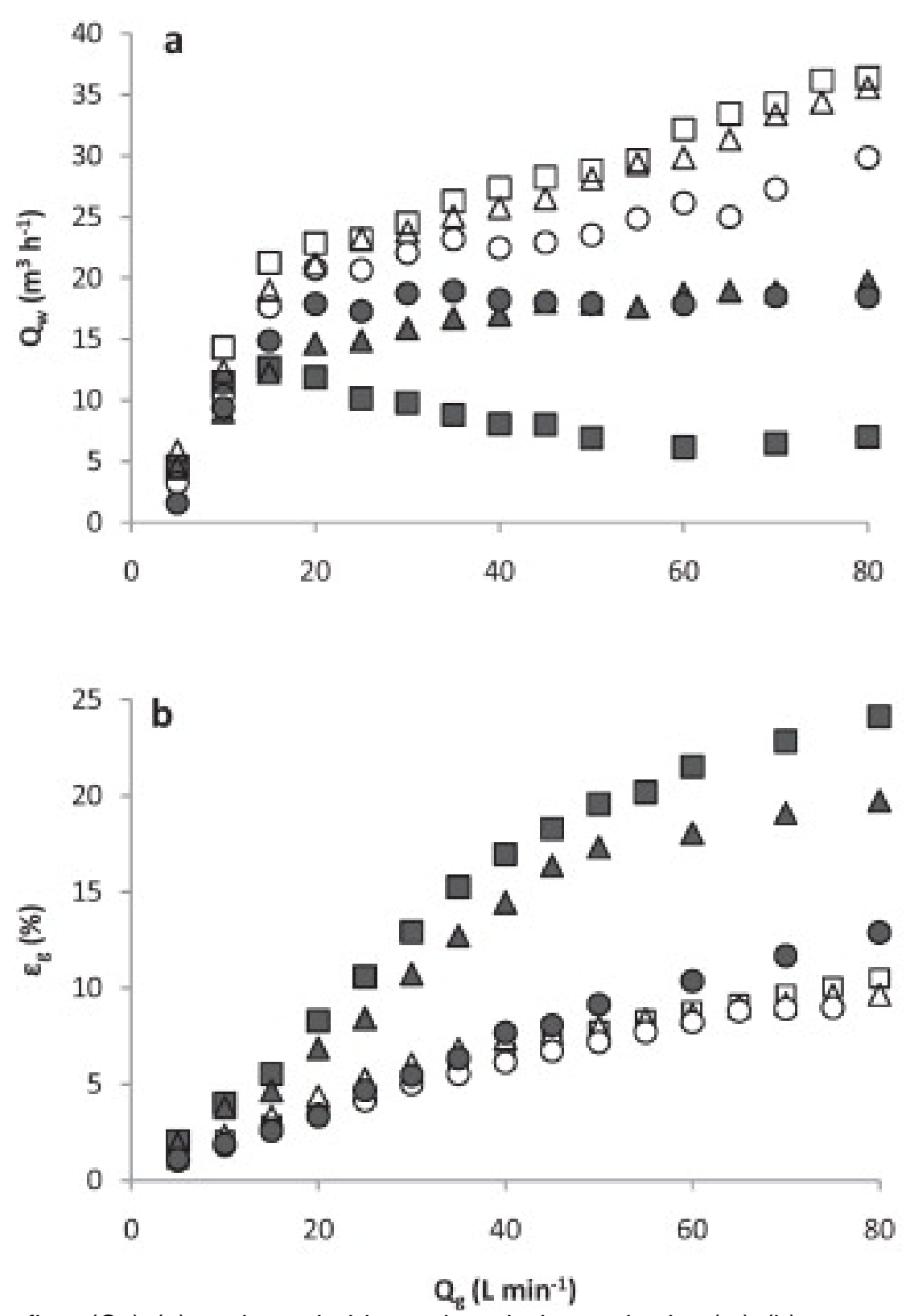

Fig. 2 : Water flow $\left(Q_{w}\right)(a)$ and gas holdup values in internal tube $\left(\varepsilon_{g}\right)(b)$ versus air flow $\left(Q_{g}\right)$ for different type of air injectors in fresh (white) and sea water (black), with a pipe length of $6 \mathrm{~m}$ and a lift of $0 \mathrm{~m}$.

With fresh water, the effect of air injector type on water flow was limited; however it seemed to be slightly smaller with open tube injectors than with diffusers, probably due to poor air distribution inside the inner pipe (air moved closely to the pipe wall during the first meter). It has been found that airlift pump efficiency is higher when bubble distribution is homogenous in the rising tube (Khalil et al., 1999), so central air injection with limited obstruction to water flow is recommended (Parker and Suttle, 1987).

Gas holdup in fresh water was calculated using Eq. (1). It was similar for all air injectors tested and varied from 0 to $10 \%$ with increasing airflow rate (Fig. $2 \mathrm{~b}$ ). With fresh water, the micro and fine bubbles $(<3 \mathrm{~mm})$ coalesced rapidly and air injector characteristics had no effect on gas holdup or on 
water flow rate (Degremont, 1978; Parker and Suttle, 1987). Thus, use of a specific micro or fine bubble air injector requiring additional energy does not increase water flow rate and is not economical (Nicklin, 1963; Parker and Suttle, 1987; Loyless and Malone, 1998; Awari et al., 2004).

The water delivery capacity of the vacuum airlift was compared to theoretical values obtained from two prediction models of liquid circulation velocity in fresh water (Fig. 3). The model of Nicklin (1963) is presented in Eq. (3) and was defined for an airlift functioning with a riser tube as:

$$
\frac{Q_{G}}{\varepsilon_{G} A}=1.2 \frac{Q_{G}+Q_{w}}{A}+0.35(g D)^{1 / 2}
$$

where $A$ is the cross sectional area of the airlift $\left(\mathrm{m}^{2}\right)$ and $D$ the diameter of the airlift $(\mathrm{m})$. The model of Chisti et al. (1988) is presented in Eq. (4) and was defined for an airlift composed of a riser tube and a downcomer tube as:

$$
U_{L}=\left[\frac{2 g H s\left(\varepsilon_{R}-\varepsilon_{D}\right)}{K\left(A_{R} / A_{D}\right)^{2} 1 /\left(1-\varepsilon_{D}\right)^{2}}\right]^{0.5}
$$

where $U_{L}$ is the liquid velocity $\left(m^{-1}\right), A_{R}$ is the cross sectional area of the riser tube $\left(m^{2}\right), A_{D}$ is the cross sectional area of the downcomer tube $\left(\mathrm{m}^{2}\right), \varepsilon_{R}$ is the gas holdup in the riser tube and $\varepsilon_{D}$ is the gas holdup in the donwcomer with $\varepsilon_{D}=0,89 \varepsilon_{R} . K$ is the frictional loss coefficient defined in Eq. (5) as:

$$
K=11.402\left(\frac{A_{D}}{A_{B}}\right)^{0.789}
$$

where $A_{B}$ is the free area for liquid flow between the riser and downcomer tubes $\left(m^{2}\right)$. 


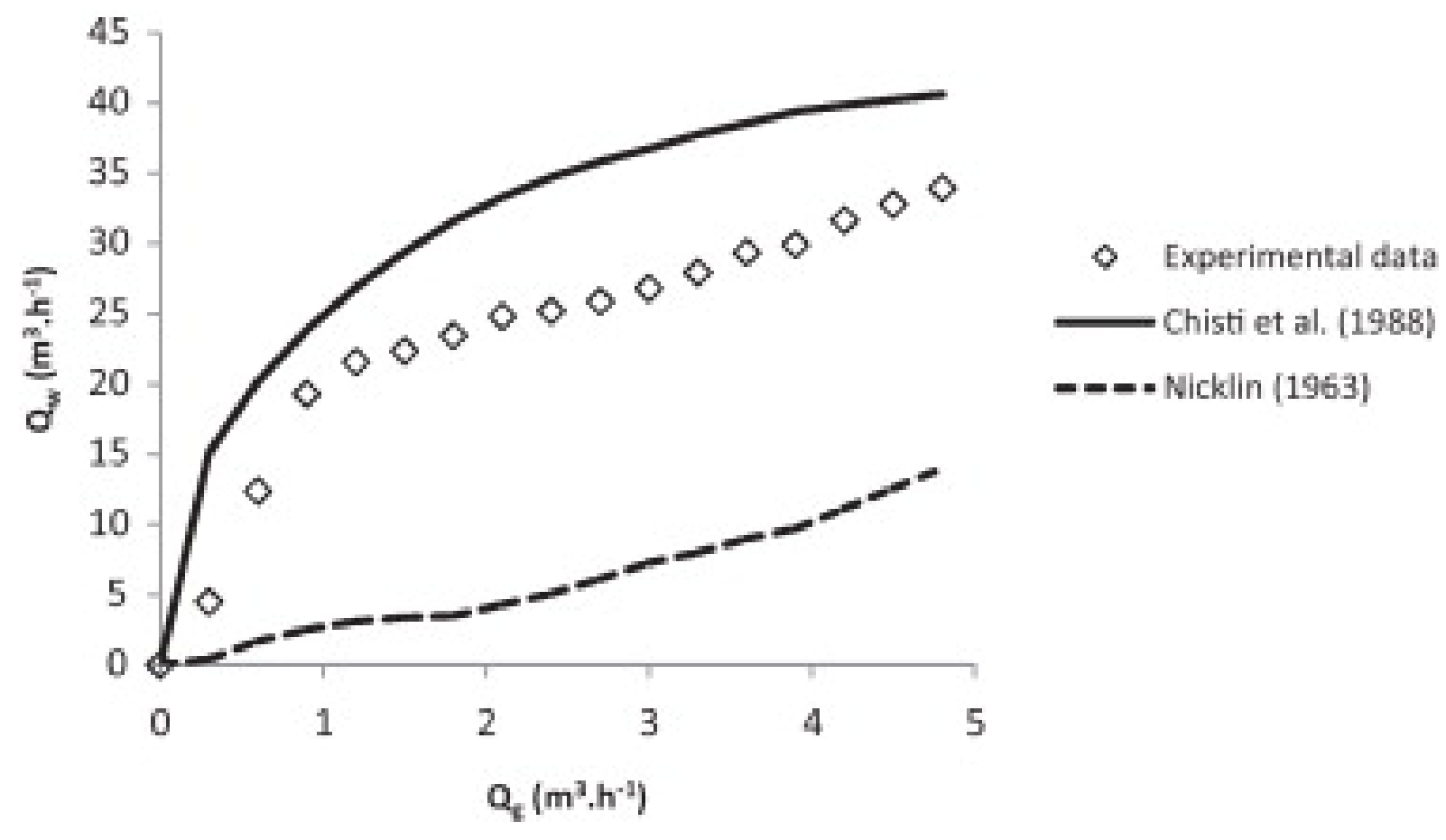

Fig. 3 : Comparison between experimental water flows $\left(Q_{w}\right)$ versus airflow $\left(Q_{g}\right)$ obtained with the vacuum airlift in fresh water (pipe length of $6 \mathrm{~m}$, no lift height) and theoretical water flow values calculated with the models of Nicklin (1963) and Chisti et al. (1988).

The theoretical water flow rates calculated from the model of Nicklin (1963) were quite different from our experimental data as they increased linearly from 0 to $15 \mathrm{~m}^{3} \mathrm{~h}^{-1}$ with airflow (Fig. 3). The theoretical values obtained from the model of Chisti et al. (1988) were closer to our experimental data and followed the same tendency until a maximum value of around $40 \mathrm{~m}^{3} \mathrm{~h}^{-1}$. This may be explained by the fact that the model of Chisti et al. (1988) takes into account the differences in gas holdup between the riser and downcomer tubes.

Except at low airflow rates, water flows obtained with sea water were lower than those obtained with fresh water and no bubble coalescence was observed (Fig. 2a-b).

For airflow rates higher than $20 \mathrm{~L} \mathrm{~min}^{-1}$, a constant water flow of about $20 \mathrm{~m}^{3} \mathrm{~h}^{-1}\left(300 \mathrm{~L} \mathrm{~min}^{-1}\right)$ was reached with fine and large bubbles, whereas water flow was decreased with microbubbles. At an airflow rate of $80 \mathrm{~L} \mathrm{~min}^{-1}$, water flows were two times lower (open tube and fine bubbles) or 6 times lower (microbubbles) than with fresh water. The specific low performance observed with microbubbles can be explained by the presence of some of them in the downcomer tube: when water circulation velocity increased, the smallest bubbles were pulled along the downcomer, creating a flow resistance which slowed down superficial liquid velocity. This phenomenon had already been observed in fresh water by Yu et al. (2008). Sea water substantially enhances this phenomenon. Moreover, instability was observed with the use of microbubbles: water flow velocity successively increased and decreased. When it increased, the downcomer tube was filled in with microbubbles and when it slowed down, it was emptied of bubbles. This phenomenon is repeated cyclically, resulting in low water flow.

Gas holdup was more substantial with sea water than with fresh water and increased with decreasing bubble size (Fig. 2b). It ranged from 0 to $13 \%$ for open tube diffusion, from 0 to $20 \%$ for fine bubble diffusion and from 0 to $25 \%$ for microbubble diffusion. Even when gas holdup appeared higher than in fresh water, water flow remained lower. This point perfectly illustrates the determining role of bubble rising velocity: if bubble size decreases, air uprising velocity also decreases and the instantaneous water shift is lower. The characteristics of the water significantly impacts bubble size and airlift performances, however few studies have tried to relate bubble size to water salinity. Recently, Kawahara et al. (2009) showed that the difference in bubble coalescence probably depends on water surface tension and on the presence of dissolved substances. Ruen-ngam et al. (2008) explained that the difference in bubble size distribution between fresh and saline water is due to two factors: a hydrophilic repulsive force, which inhibits bubble coalescence and Laplace pressure, which controls the coalescence and breakup of bubbles. They explained that salinity decreases the surface 
tension of water, significantly affecting bubble size distribution and that the presence of electrolytes in sea water inhibits bubble coalescence and decreases bubble uprising velocity. Despite the differences in bubble size distribution between fresh and saline water, they found that the effect of salinity on gas holdup was only marginal, which we found true only for open tube air injection (Fig. 2b). Our results with open tube air diffusion are similar to their results with aeration provided by air injection through 30 holes of $1 \mathrm{~mm}$ in diameter.

\subsection{Air flow, pipe length, lift height and vacuum}

Variations in pipe length affect the vacuum at the top of the vacuum airlift: for a vacuum airlift of 2 , 4 or $6 \mathrm{~m}$, negative pressure levels were $-0.15,-0.3$ and -0.5 bar respectively. Water flow was also affected by pipe length variations. A higher vacuum airlift resulted in higher water flow under the same conditions for both fresh and sea water (Fig. 4a-b). The results at $1 \mathrm{~m}$ were reported by Loyless and Malone (1998) for fresh water and by Moran (2010b) for sea water. Both studies used airlifts of different dimensions (vertical tube of $50 \mathrm{~mm}$ OD) but with similar lift heights. An increase of a $2 \mathrm{~m}$ pipe length provided an increase in water flow of $6 \mathrm{~m}^{3} \mathrm{~h}^{-1}\left(100 \mathrm{~L} \mathrm{~min}^{-1}\right)$ with fresh water and $3 \mathrm{~m}^{3} \mathrm{~h}^{-1}(50 \mathrm{~L}$ $\mathrm{min}^{-1}$ ) with sea water. Increasing pipe length corresponds to increased air injection depth in a regular airlift, which results in increased water flow (Nicklin, 1963; Reinemann, 1987; Parker and Suttle, 1987; Wurts et al., 1994; Awari et al., 2004). However, airlift pump efficiency remains constant beyond $8 \mathrm{~m}$ of injection depth (Degremont, 1978).

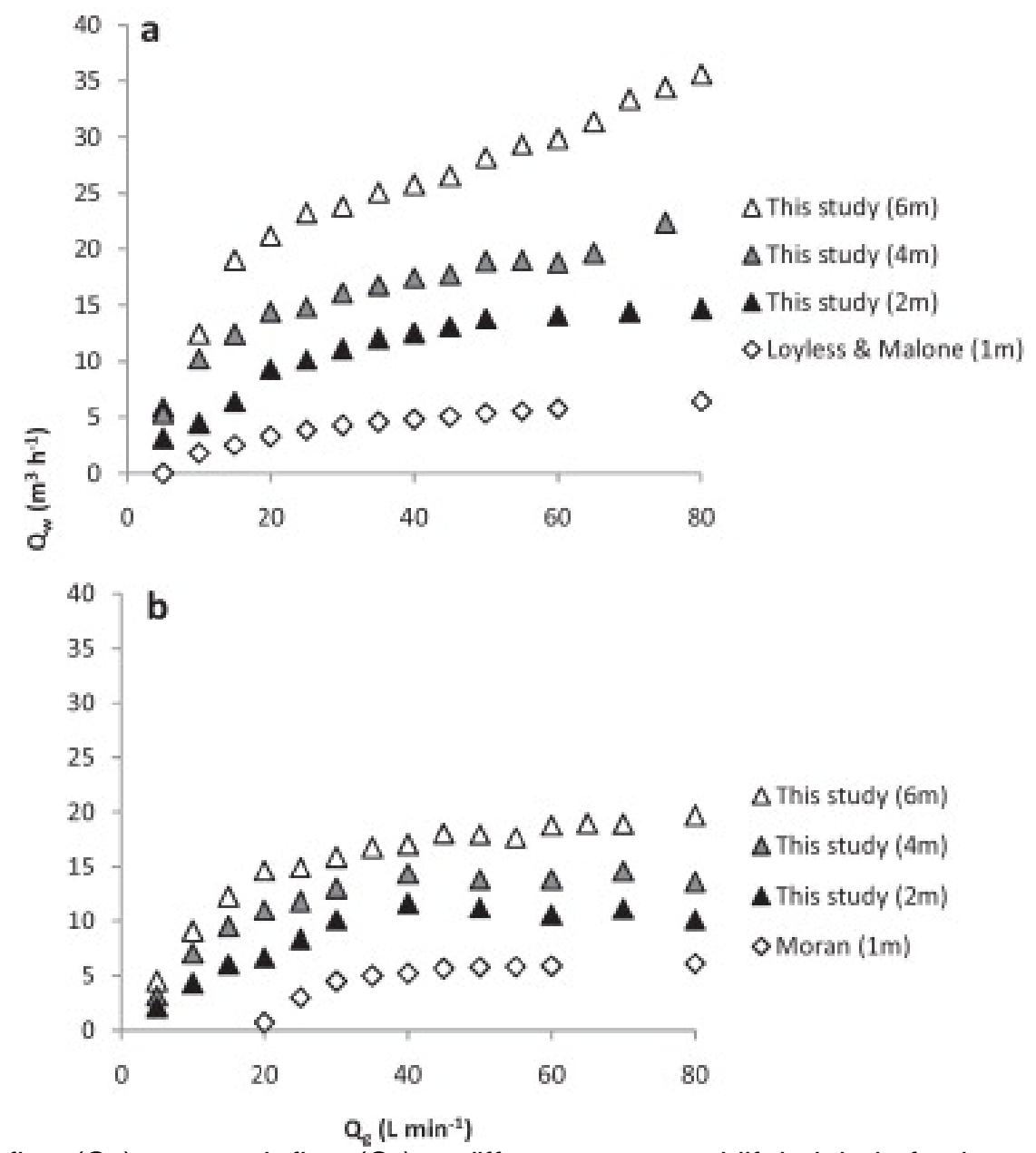

Fig. 4 : Water flow $\left(Q_{w}\right)$ versus air flow $\left(Q_{g}\right)$ at different vacuum airlift height in fresh water (a) and sea water (b) with fine bubble air injection and no lift height. Results of Loyless and Malone (1998) and Moran (2010b) with an airlift of $1 \mathrm{~m}$ high are also represented. 
With fresh water, lift height had a negative effect on water flow irrespective of pipe length and air flow (Fig. 5). A $10 \mathrm{~cm}$ increase in lift height was equivalent to a more than $30 \%$ decrease in water flow. A $6 \mathrm{~m}$ high vacuum airlift with an airflow of over $40 \mathrm{~L} \mathrm{~min}^{-1}$ resulted in a water flow of over $10 \mathrm{~m}^{3}$ $\mathrm{h}^{-1}\left(160 \mathrm{~L} \mathrm{~min}^{-1}\right)$, even if the lift height was $0.3 \mathrm{~m}$. However, for the 4 or $2 \mathrm{~m}$ high vacuum airlifts, in all cases water flow was under $8 \mathrm{~m}^{3} \mathrm{~h}^{-1}\left(130 \mathrm{~L} \mathrm{~min}^{-1}\right)$ or null with a lift height of $0.3 \mathrm{~m}$. In such situations, air should always be injected at a flow rate above $20 \mathrm{~L} \mathrm{~min}^{-1}$ to ensure that bubble buoyancy is sufficient to lift the water. These results are consistent with those presented by Loyless and Malone (1998) and Moran (2010b), even if their water flow values were four times lower.

The negative effect of lift height on water flow was reduced with smaller bubble size (Table 2). Microbubbles reduced by $15 \%$ and $52 \%$ the decrease in water flow for lifts between 0 and $0.3 \mathrm{~m}$ in fresh and sea water respectively. Smaller bubbles result in higher gas holdup values and thus in higher lift availability. Water flow increased with increasing bubble size but decreased with increasing lift height. For riser tube diameters larger than $40 \mathrm{~mm}$, injectors are necessary to obtain an acceptable lift height (Awari et al., 2004). In RAS, water flow decreased rapidly despite the use of injectors when the different water treatment processes requiring head, like media filters for example, were added (Loyless and Malone, 1998). Airlift positioning in RAS therefore has a significant impact on its performance (Loyless and Malone, 1998). Because vacuum airlift should be implemented with no or very low head loss for an acceptable recycled water ratio to be obtained, it can only be used with low head systems.

\begin{tabular}{|c|c|c|c|c|c|c|}
\hline \multirow[t]{2}{*}{ Lift height (m) } & \multicolumn{3}{|l|}{ Fresh water } & \multicolumn{3}{|l|}{ Sea water } \\
\hline & Open tube & Fine bubbles & Micro bubbles & Open tube & Fine bubbles & Micro bubbles \\
\hline 0 & 22.1 & 23.8 & 24.5 & 18.8 & 15.9 & 9.8 \\
\hline 0.1 & 13.5 & 15.8 & 16.7 & 14.9 & 14.6 & 8.1 \\
\hline 0.2 & 5.8 & 11.7 & 13.1 & 8.1 & 10.6 & 6.2 \\
\hline 0.3 & 0 & 2.7 & 3.6 & 0 & 6 & 4.7 \\
\hline
\end{tabular}

Table 2 : Water flow $\left(\mathrm{m}^{3} \mathrm{~h}^{-1}\right)$ versus lift height for different types of air injection in fresh and sea water with a $6 \mathrm{~m}$ high vacuum airlift and an airflow of $30 \mathrm{~L} \mathrm{~min}^{-1}$.

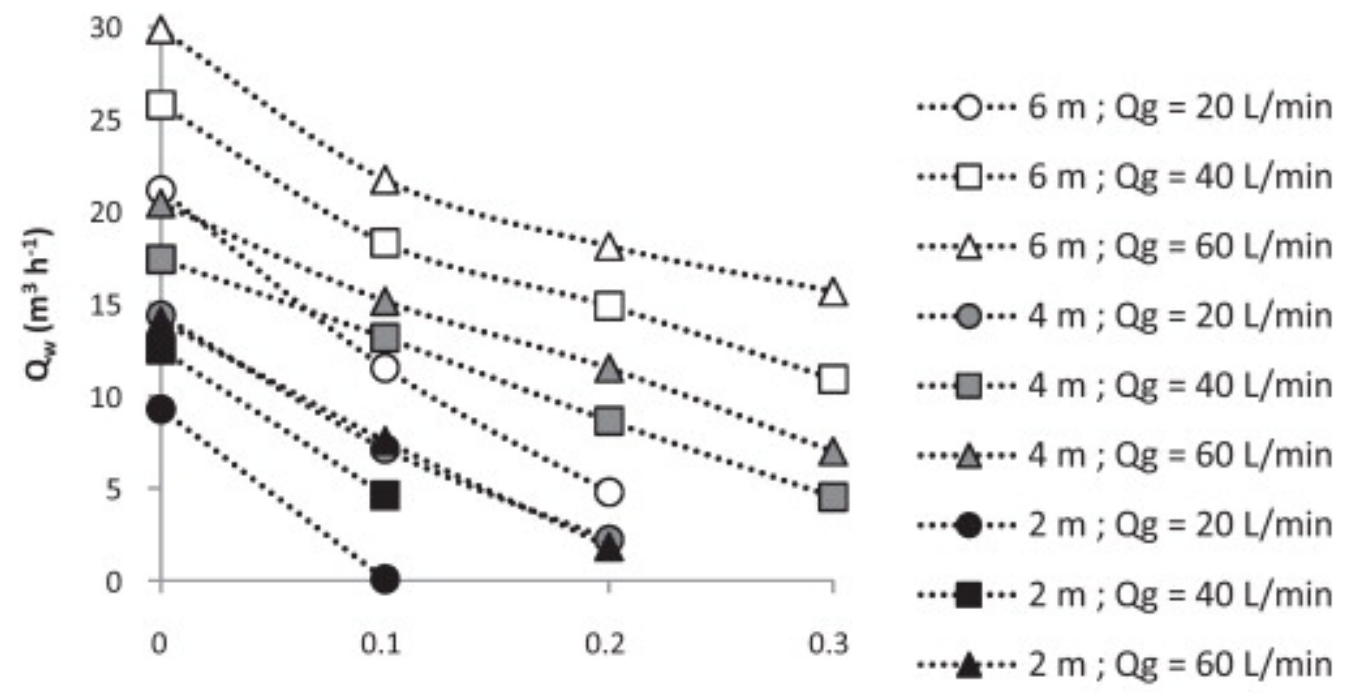

Lift height ( $\mathrm{m}$ )

Fig. 5 : Water flow $\left(\mathrm{Q}_{\mathrm{w}}\right)$ versus lift height at different vacuum airlift heights $(2,4$ and $6 \mathrm{~m})$ and for different air flows $\left(20,40\right.$ and $\left.60 \mathrm{~L} \mathrm{~min}^{-1}\right)$ in fresh water and with fine bubble air injection.

Integration of all the results obtained with experiments on pipe length, lift height and air flow variations in fresh water made it possible to develop an empirical model for predicting the water flow rate of 2 to $6 \mathrm{~m}$ high vacuum airlifts with 20 to $80 \mathrm{~L} \mathrm{~min}^{-1}$ of air flow injection and for lift heights ranging between 0 and $0.3 \mathrm{~m}$. The empirical equation of the model is presented in Eq. (6) as: 
where: $Q_{w}$ is the water flow $\left(m^{3} h^{-1}\right) ; H$ is the pipe length $(m) ; L$ is the lift height $(m)$ and $Q_{g}$ is the air flow $\left(L \mathrm{~min}^{-1}\right)$. Figure 6 shows a good correlation $\left(R^{2}=0.964\right)$ between the predicted and the experimental data.

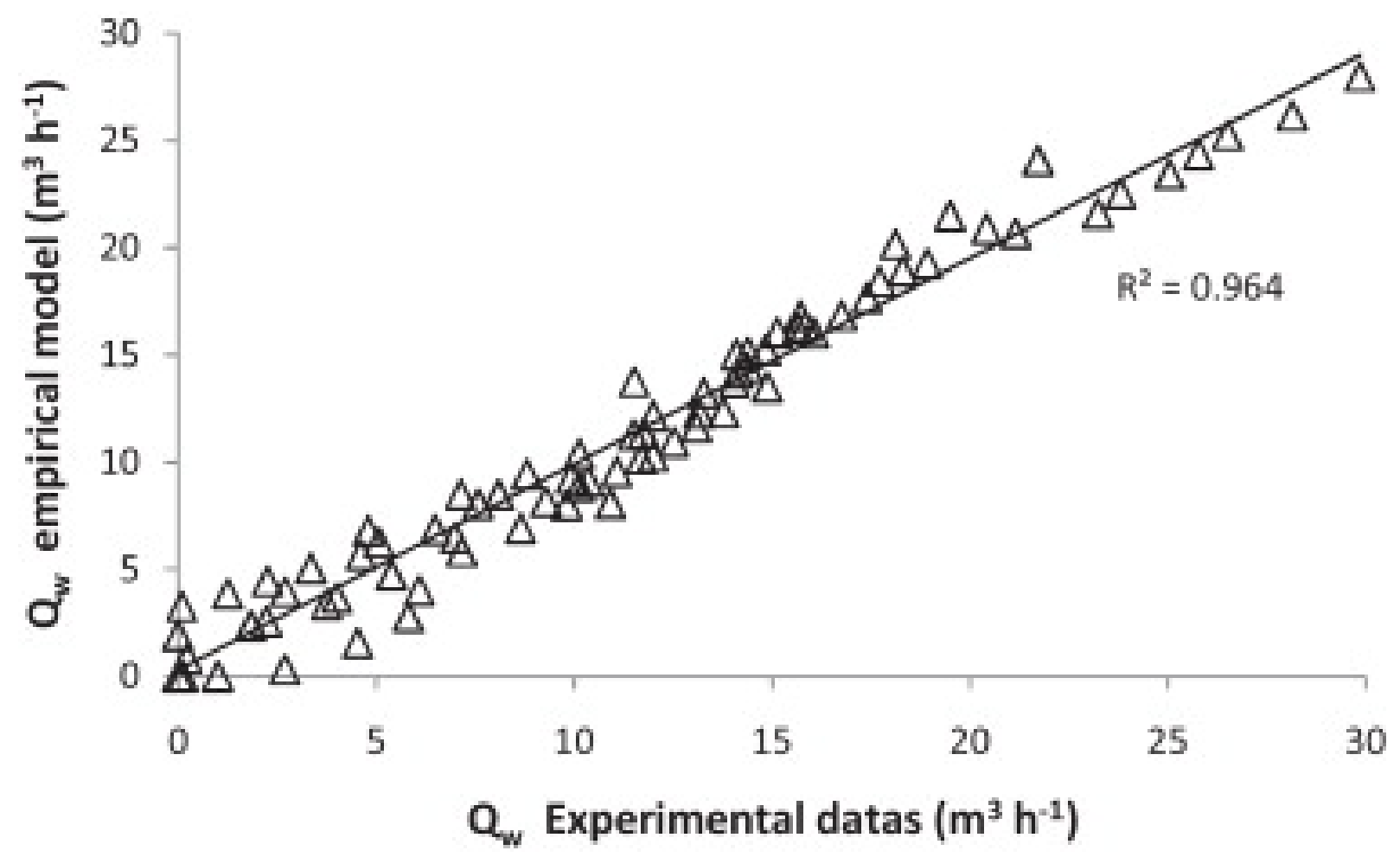

Fig. 6 : Empirical model versus experimental data for water flow in the vacuum airlift of different pipe lengths, lift heights and air flows.

\subsection{Airlift pump efficiency and submergence ratio}

Airlift pump efficiency was calculated using Eq. (2) (Nicklin, 1963; Reinemann, 1987; Kassab et al., 2009; Moran, 2010b). Vacuum airlift efficiency shows a coherent negative parabolic relationship with water flow (Fig. 7a-b). 

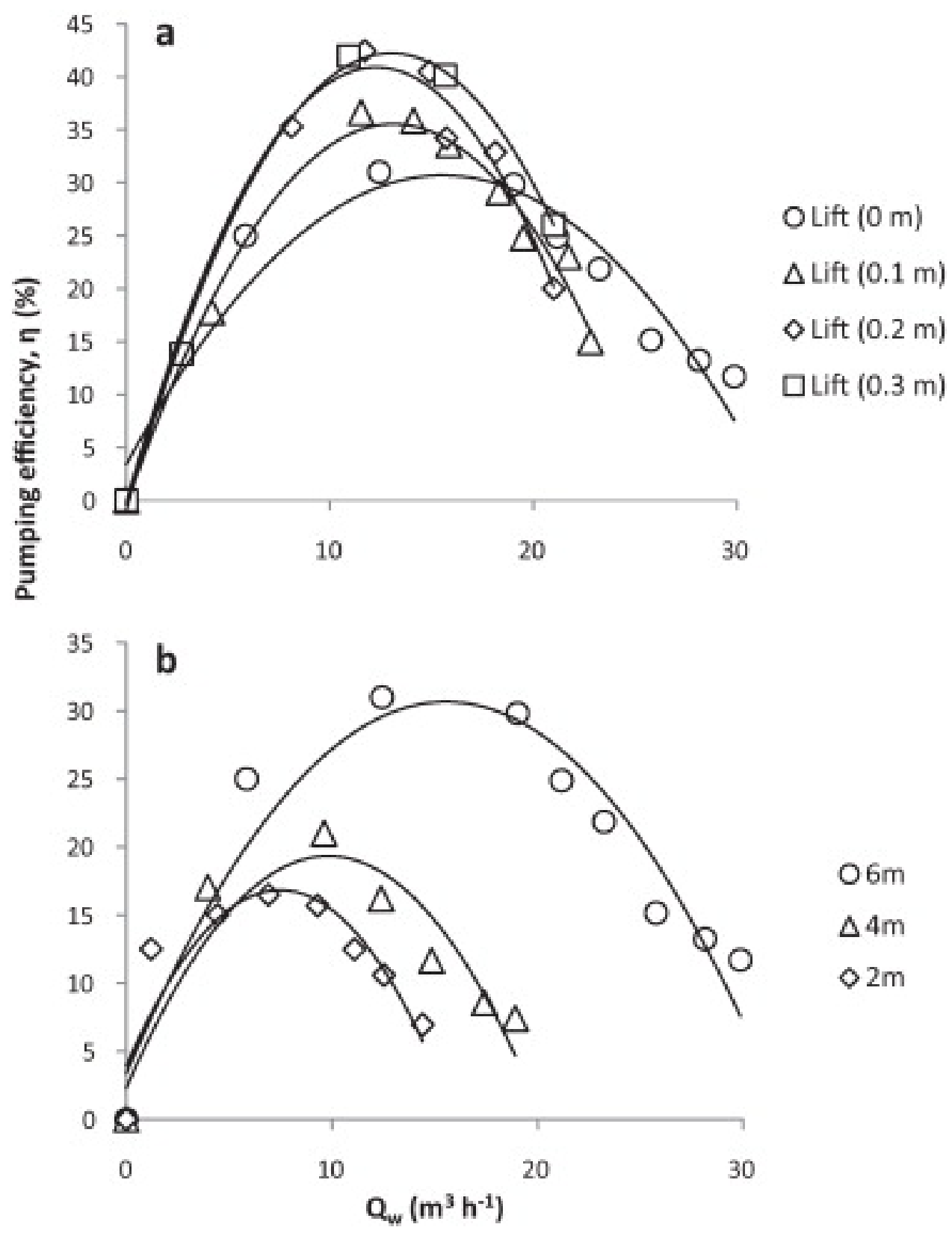

Fig. 7 : Airlift pumping efficiency versus water flow $\left(\mathrm{Q}_{w}\right)$ at different lift heights with a $6 \mathrm{~m}$ high vacuum airlift (a) and at different vacuum airlift heights with no lift (b) in fresh water and with fine bubble injection)

This kind of relationship has already been described in previous studies (Nicklin, 1963; Kassab et al., 2009; Moran, 2010b). Efficiency increases with water flow (and thus air flow) and reaches a maximum before decreasing. For a $6 \mathrm{~m}$ high vacuum airlift in fresh water, maximum pumping efficiency for a water flow of $12 \mathrm{~m}^{3} \mathrm{~h}^{-1}\left(200 \mathrm{~L} \mathrm{~min}^{-1}\right)$ varied from 30 to $40 \%$, with the maximum value obtained when the vacuum airlift functioned with a lift ranging between 20 and $30 \mathrm{~cm}$ (Fig. 7a). The efficiencies obtained by Nicklin (1963) ranged between 20 and $55 \%$ depending on airlift diameter, those obtained by Kassab et al. (2009) ranged between 10 to $45 \%$ depending on the submergence ratio and those obtained by Moran (2010b) were around $25 \%$ depending on lift height. With no lift height, the highest efficiencies (15 to $30 \%$ ) were obtained for water flows ranging from 7 to $16 \mathrm{~m}^{3} \mathrm{~h}^{-1}$ (120 to $270 \mathrm{~L} \mathrm{~min}{ }^{-1}$ ), corresponding to air flows ranging from 10 to $20 \mathrm{~L} \mathrm{~min}^{-1}$ depending on pipe length (Fig. 7b). This range of air flows corresponds to a slug flow which correspond to the best flow for airlift performance (Kassab et al., 2009). It is therefore not justified to increase air flow rates beyond the optimum value (Awari et al., 2004). Since it stands to reason that an increase in injection depth leads to an increase in pumping efficiency, it is quite surprising that an increase in lift height, which leads to 
a decrease in water flow, may result in better airlift pumping efficiency. Nevertheless, these results are consistent with those obtained by Moran (2010b) with lift heights varying from 0.1 to $0.25 \mathrm{~m}$. We can however suppose that the better efficiencies obtained with high lift height are due to the relatively high water flows measured under these conditions.

In airlift pump design, submergence ratio is a significant factor for pumping efficiency (Kassab et al., 2007). The more this ratio increases (less lift or higher injection depth), the higher the water flow rate of the airlift pump (Wurts et al., 1994; Loyless and Malone, 1998; Awari et al., 2004). Conversely, when the submergence ratio is too small (low injection depth or high lift), the water flow rate is low, leading to higher pumping functioning costs (Parker and Suttle, 1987; Loyless and Malone, 1998; Awari et al., 2004). The major problem with airlift pumps is that high submergence ratios are required to obtain the same efficiency as other types of pumps (Kassab et al., 2007). With these systems, functioning with low or no lift height i.e. with an injection depth equal to pipe length produces a submergence ratio close to 1 .

\subsection{Secondary role of vacuum}

As it is necessary to increase pipe length for increased negative pressure values in the vacuum airlift (Table 1), the experiment with a static airlift showed that vacuum at the top of the airlift modified gas holdup values (Fig. 8a). For a given air flow, an increase in vacuum (i.e. a decrease in pressure) leads to an increase in gas holdup for all the types of water tested. With fresh water, gas holdup increased from 6 to $9 \%$ under atmospheric pressure and from 8 to $13 \%$ under a vacuum of 0.3 barA (-0.7 bar), depending on the quantity of air injected. With sea water, the same pattern of variation was observed with an increase from 11 to $20 \%$ under atmospheric pressure and from 21 to $23 \%$ under a vacuum of 0.3 barA ( -0.7 bar), depending on the quantity of air injected. This increase is due to gas expansion with vacuum. A larger vacuum results in larger bubble volume, according to the ideal gas law. Increasing vacuum airlift height and thus negative pressure values resulted in larger bubbles and improved water flow (Fig. 4a-b). With sea water, an increase in air flow from 20 to $40 \mathrm{~L} \mathrm{~min}^{-1}$ leads to a variable increase in gas holdup of $5 \%$ at atmospheric pressure and of $1 \%$ at 0.3 barA ( -0.7 bar) (Fig. 8a). Conversely, air flow rates increased from 40 to $60 \mathrm{~L} \mathrm{~min}^{-1}$ led to a variable decrease in gas holdup from $3 \%$ at atmospheric pressure to $1 \%$ at 0.3 barA $(-0.7$ bar). This was probably due to bubble coalescence when air flow was too high. In the static airlift, bubble coalescence was observed in the tube when the air volume was high, resulting in decreased gas holdup and an increase in bubble size.

The quantity of air injected in the airlift increased spontaneously with the negative pressure level which reduces air injection pressure (Fig. 8b). It was then necessary to limit air injection to maintain a constant air flow during monoparametric studies on the effect of negative pressure level. Moreover, when the injection depth was high, an increase in vacuum compensated for injection pressure and thus increased air flow (Fig. 8b).

Finally, addition of a vacuum (1) increased air flow in the airlift by a reduction of air injection pressure, (2) increased gas holdup, leading to higher average bubble size and thus to higher water circulation velocity (Awari et al., 2004) and (3) increased water flows with pipe length without increasing air injection pressure. 

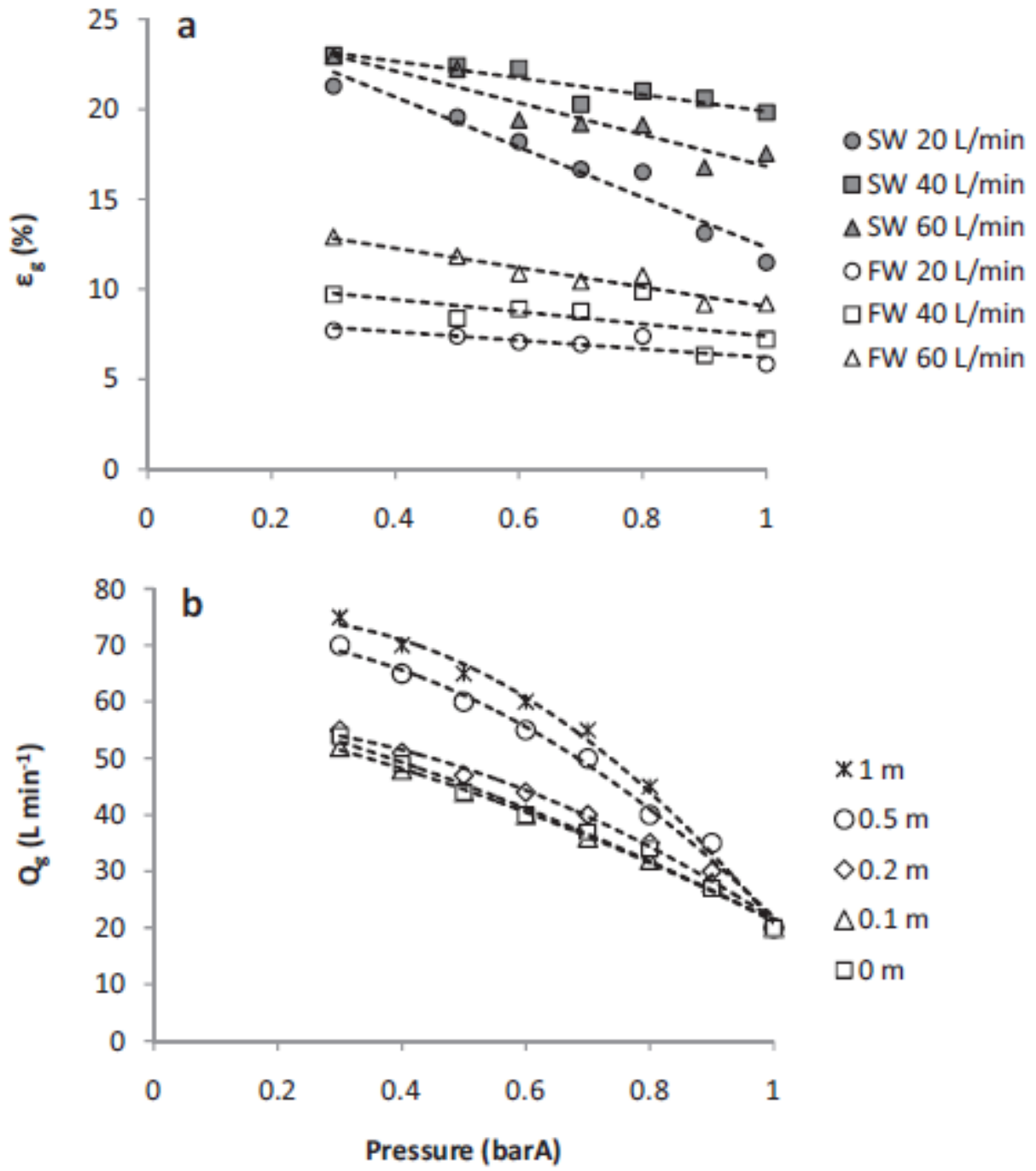

Fig. 8. Static gas holdup $\left(\varepsilon_{g}\right)$ at different air flows in fresh and sea water (a) and static air flow $\left(Q_{g}\right)$ starting from $20 \mathrm{~L} \mathrm{~min}^{-1}$ of injected air at different injection depths (b) versus negative pressure values (below atmospheric pressure.

\subsection{Test in rearing water conditions}

Water flow delivered by the vacuum airlift in rearing water conditions varied during the day according to fish feeding (Fig. 9). After feeding, the water flow increased from around $15 \mathrm{~m}^{3} \mathrm{~h}^{-1}$ (200 L $\left.\mathrm{min}^{-1}\right)$ to around $45 \mathrm{~m}^{3} \mathrm{~h}^{-1}\left(750 \mathrm{~L} \mathrm{~min}^{-1}\right)$. This increase was closely correlated to a gas holdup decrease from $22 \%$ to around $5 \%$ and a simultaneous coalescence of air bubbles that induced higher airlift pumping efficiency. Lipids present in feed reduce surface tension of sea water and enhance bubble coalescence and air rising velocity (Guyon, 2001). 


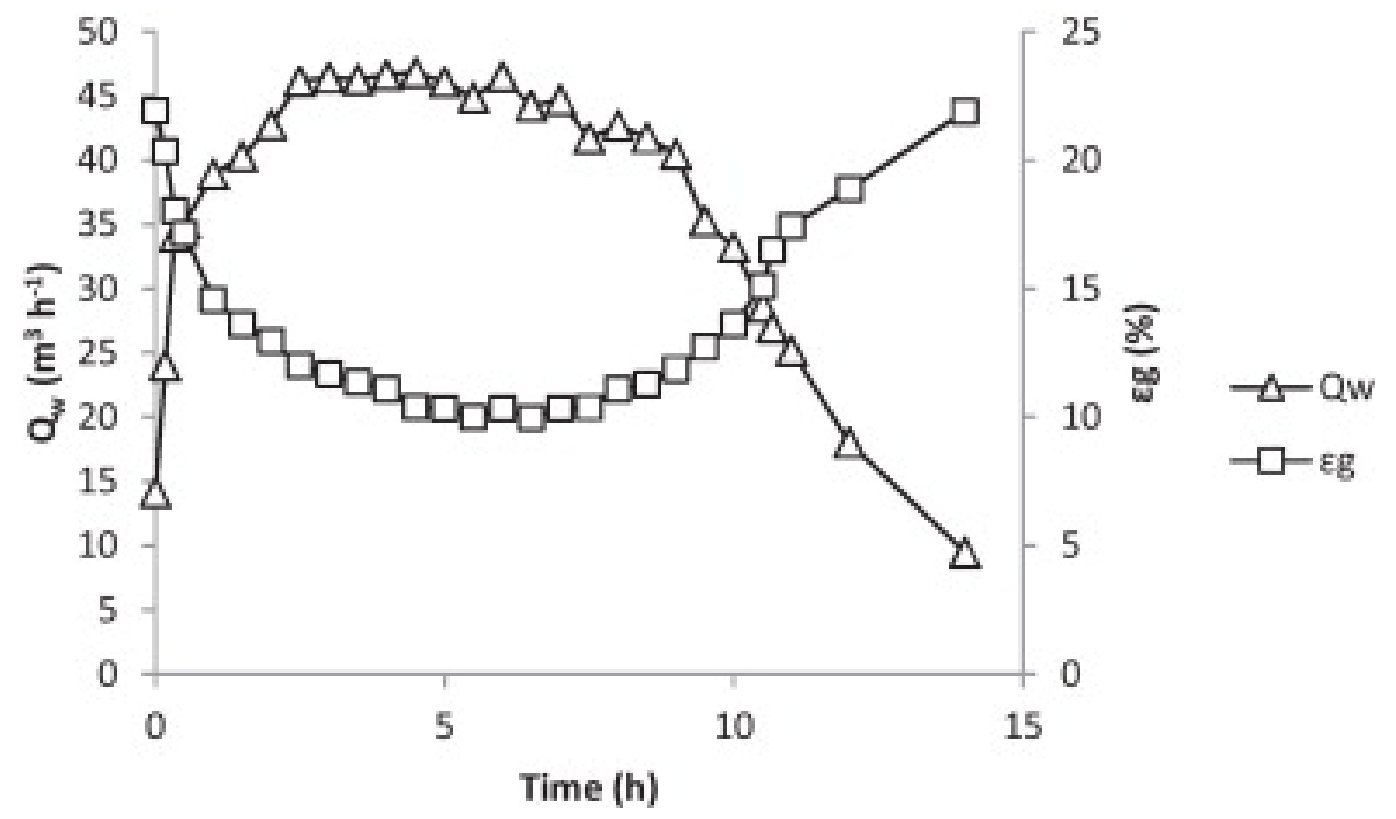

Fig. 9: Water flow $\left(\mathrm{Q}_{w}\right)$ and gas holdup $\left(\varepsilon_{\mathrm{g}}\right)$ versus day time after feeding in a rearing tank (feeding started at Hour 0 and lasted for 4 hours, the airflow rate was $80 \mathrm{~L} \mathrm{~min}^{-1}$ with fine bubble air injection in sea water and with a $6 \mathrm{~m}$ high vacuum airlift).

Just after feeding, water flows were similar to those obtained with fresh water at bubble coalescence (Fig. 10). They were even $15 \%$ higher when the air flow rate was above $30 \mathrm{~L} \mathrm{~min}^{-1}$. This result is related to the increase in airlift pumping efficiency associated with the characteristics of the water explained by Khalil et al. (1999). A few hours after feeding, the rearing sea water recovered its initial characteristics and water flows varied accordingly (Fig. 9 and 10).

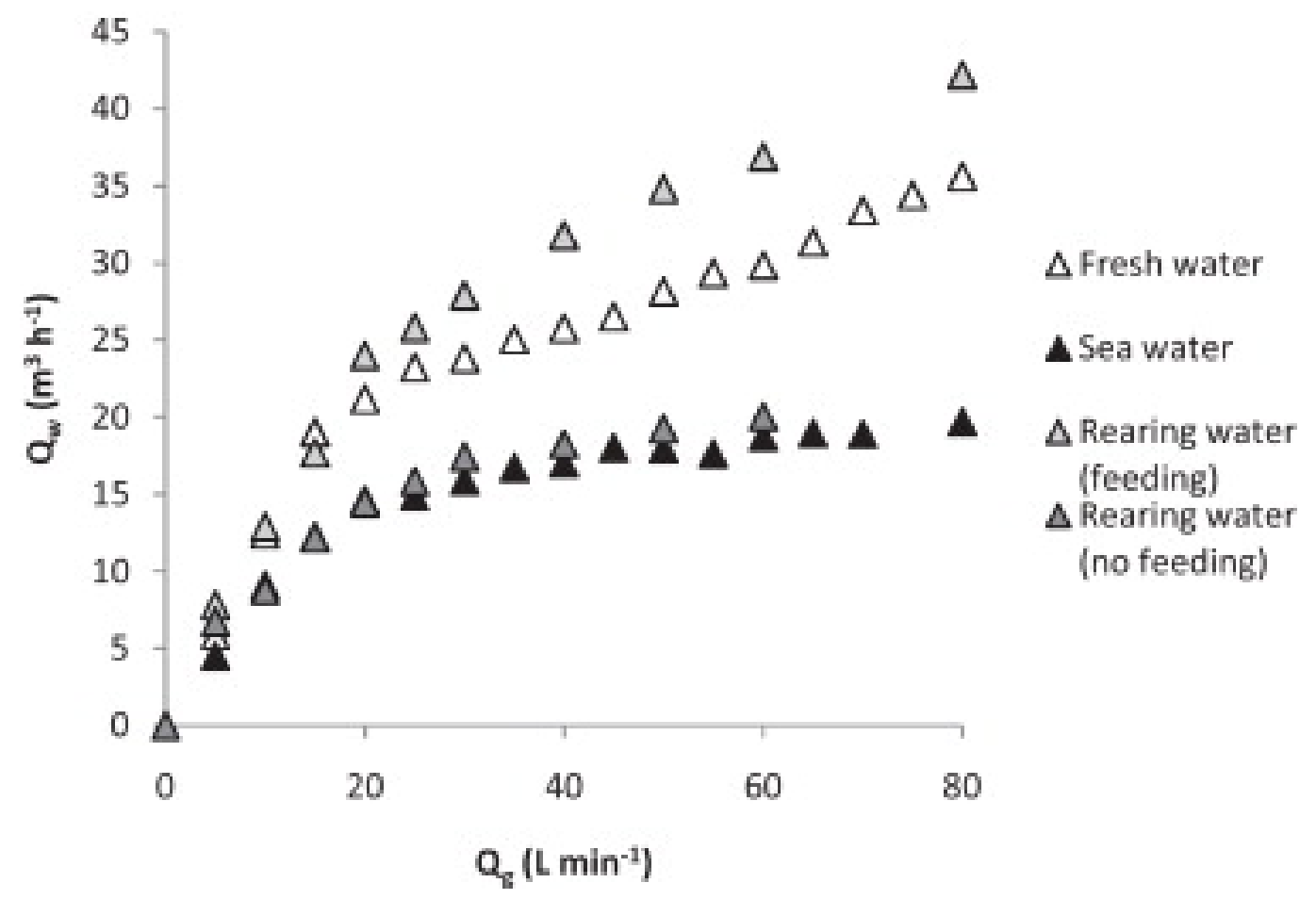

Fig. 10 : Water flow $\left(Q_{w}\right)$ versus air flow $\left(Q_{g}\right)$ for different types of water with a $6 \mathrm{~m}$ high vacuum airlift, fine bubble injection and no lift height. 
The lift height with the vacuum airlift depended on the type of water used (Fig. 11). Lift height was greater with sea water (up to $0.8 \mathrm{~m}$ ) than with fresh water (up to $0.6 \mathrm{~m}$ ). With sea water during feeding, lift height was only $0.4 \mathrm{~m}$.

Lift height is correlated to gas holdup and a low gas holdup (as in sea water under fed conditions) corresponds to a poor available head, but also to a higher water flow for a given air flow (Fig. 11). In low head designed RAS with a maximum head of $0.3 \mathrm{~m}$, the vacuum airlift can circulate 10 $\mathrm{m}^{3} \mathrm{~h}^{-1}$ (160 L min-1) of water. For larger water transport, the vacuum airlift should be installed with lower or no head loss to maximize water flow.

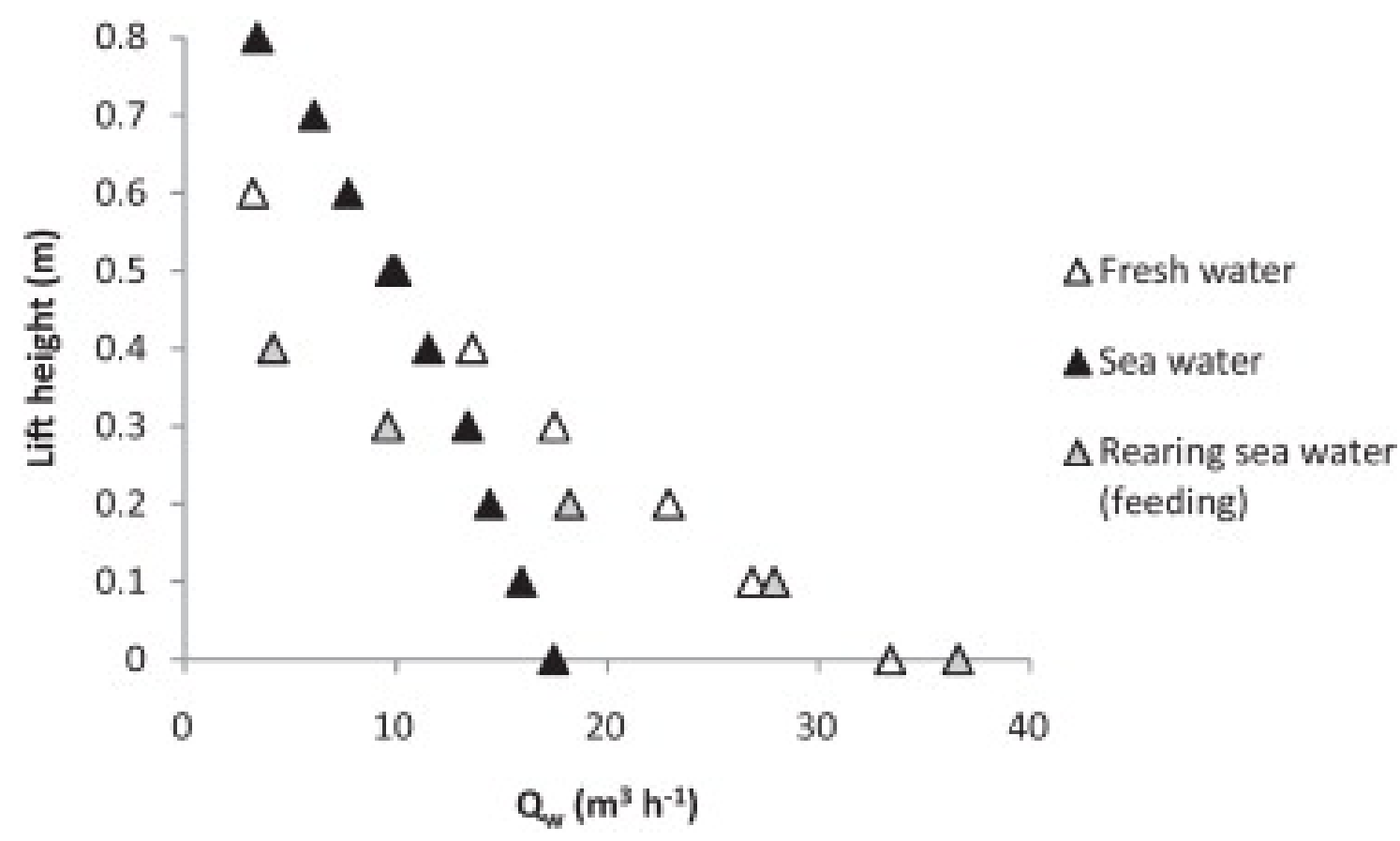

Fig. 11 : Lift height versus water flow $\left(\mathrm{Q}_{w}\right)$ for different types of water with a $6 \mathrm{~m}$ high vacuum airlift, fine bubble injection and an airflow of $60 \mathrm{~L} \mathrm{~min}$.

\subsection{Comparison of pump efficiencies}

Different types of pumps are available for water transport for RAS. It is impossible to compare them because their working conditions are completely different. Centrifugal pumps are usually used for high lift heights ranging from 2 to $16 \mathrm{~m}$ whereas airlift pumps work only at low lift heights, ranging from 0 to $0.5 \mathrm{~m}$ (Fig. 12). At low lift height and with fresh water, it is more economical to use airlift pumps rather than centrifugal pumps because their optimal efficiency is between 5 to $10 \mathrm{~m}$. In low head RAS working with a maximum head loss of $0.3 \mathrm{~m}$, a centrifugal pump consumes more than $100 \mathrm{~W}$ per meter of head and $\mathrm{m}^{3} \mathrm{~h}^{-1}$ of water transported (Fig. 12). Under the same conditions, a vacuum airlift pump (including vacuum pump with controlled system and air compressor) consumes around $60 \mathrm{~W}$, which corresponds to a consumption decrease of around $40 \%$. This result is better than the reduction of $35 \%$ mentioned in other studies (Reinemann, 1987; Awari et al., 2004; Kassab et al., 2009; Roque d'Orbcastel et al., 2009). The geometry of the airlift used and the addition of vacuum are probably the reasons for energy cost reduction. Finally vacuum airlift cannot be used if the lift height is higher than $0.6 \mathrm{~m}$ for fresh water and higher than $0.8 \mathrm{~m}$ for sea water (Fig. 11). 


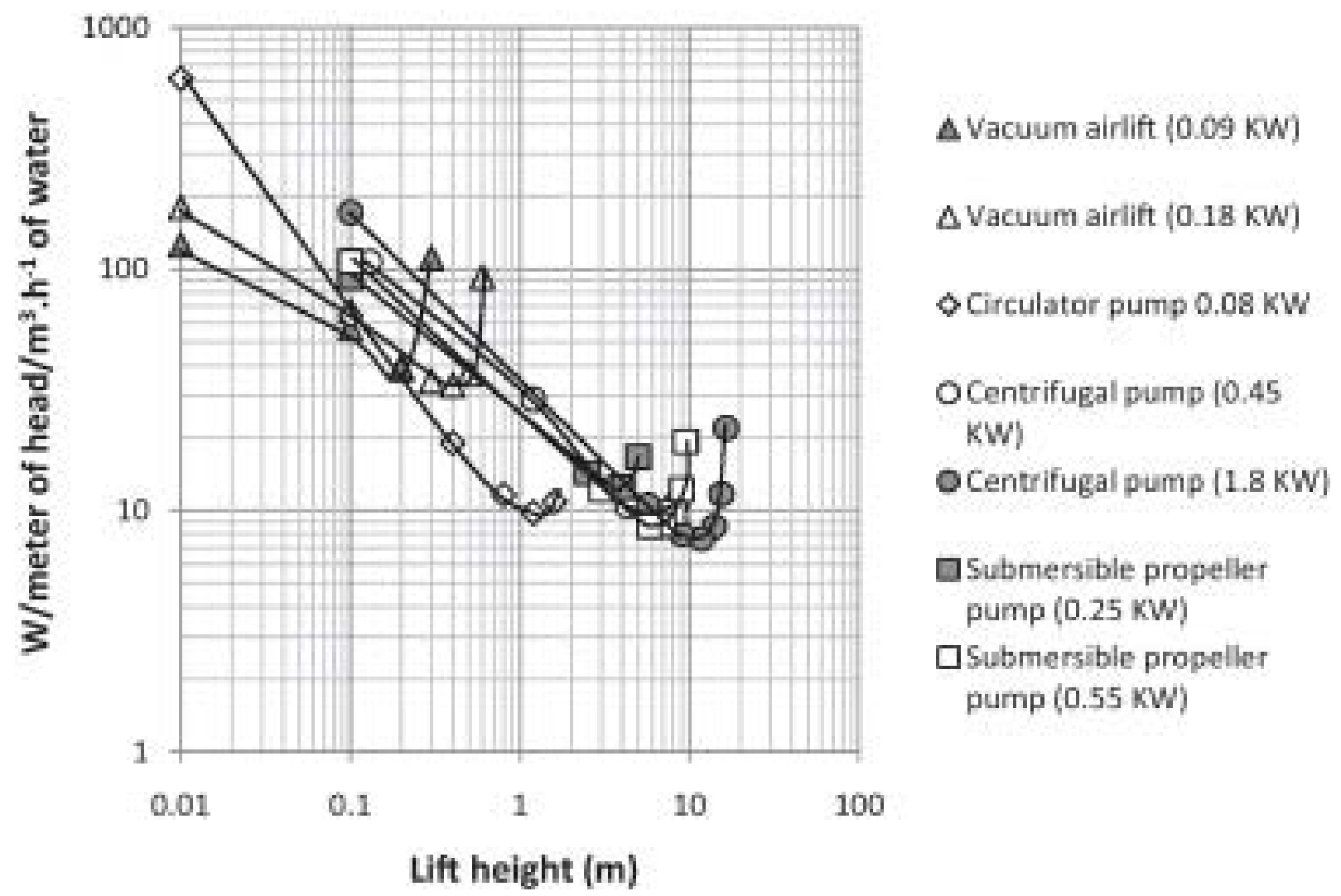

Fig. 12 : Electric consumption per meter of lift and $\mathrm{m}^{3} \mathrm{~h}^{-1}$ of water transported versus lift height $(\mathrm{m})$ for different types of pumps in fresh water.

\section{Conclusion}

Substantial differences can be observed in the functioning of vacuum airlift pumps with fresh and sea water, due to differences in gas holdup and air bubble size. With fresh water, bubble coalescence is observed and gas holdup is lower than with sea water. Water delivery capacity is higher, but the available head is lower compared to sea water. For water pumping, air injectors should not be used as they do not increase water flow and require higher injection pressure. With fresh water, the effect of pipe length, lift height and air flow on water flow were summarized using an empirical equation which allowed prediction of water flow. An increase in vacuum slightly improved airlift water delivery capacity and was used as an alternative to augment the submergence ratio without increasing injection depth. In RAS, the addition of feed rapidly increased water flow delivered by the vacuum airlift because of changes in water quality and thus in bubble size and gas holdup. In low head RAS (lift height under $0.3 \mathrm{~m}$ ), vacuum airlifts reduce the energy needed by centrifugal pumps by $40 \%$, depending on the required lift height. For higher lift heights, centrifugal pumps give better results both in terms of water flow and energy consumption. The main advantage of vacuum airlifts is that they combine three main functions: water transport, gas exchanges and foam fractionation in the same device. The vacuum airlift can thus be considered as a promising tool for water recirculation in low head aquaculture. However additional work is required to accurately predict water flow rates for different water qualities and to adapt the geometry of vacuum airlifts to various RAS designs.

\section{Acknowledgements}

We would like to thank Pierre Bosc from ARDA and the Réunion Region as well as the French National Association for Research and Technology (ANRT) for their financial support for this project. This study was made possible thanks to the cooperation of François René (IFREMER). We also wish 
to thank Julien Jacquety from COLDEP ${ }^{\circledR}$ for all his assistance and hard work, and for kindly providing the vacuum airlift.

\section{Nomenclature}

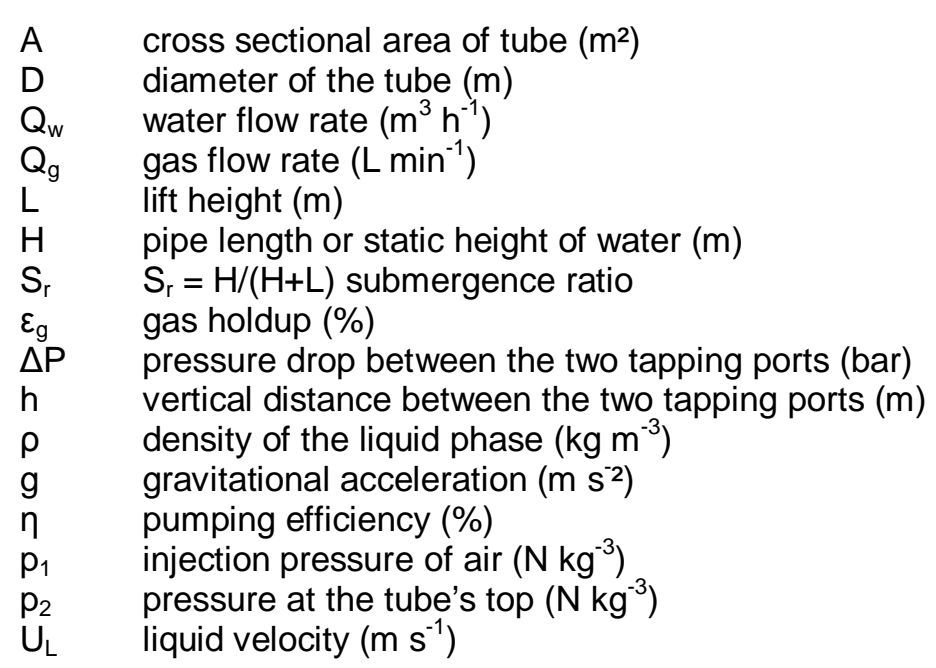

\section{References}

Awari, G.K., Ardhapurkar, P.M., Wakde, D.G., Bhuyar, L.B., 2004. Performance analysis of air-lift pump design, Proc.IMECH E Part C: J. Mech. Eng. Sci. 218, 1155-1161.

Barrut, B., Blancheton, J.P., Champagne, J.Y., Grasmick, A., 2011. Mass transfer efficiency of a vacuum airlift-Application to water recycling in aquaculture systems. Aquacult. Eng., doi: 10.1016/j.aquaeng.2011.10.004

Blancheton, J.P., Piedrahita, R., Eding, E.H., Roque d'Orbcastel, E., Lemarié, G., Bergheim, A., Fivelstad, S., 2007. Intensification of land based aquaculture production in single pass and reuse systems. Chapter 2. In: Aquaculture Engineering and Environment, p. 21-47.

Chisti, M.Y., Halard, B., Moo-Young, M., 1988. Liquid circulation in airlift reactors. Chem. Engng. Sci., 43, 451-457.

Degrémont, 1978. Mémento technique de l'eau. Technique et Documentation. Huitième édition. Paris $1203 \mathrm{p}$.

Guyon, E., Hulin, J.P., Petit, L., 2001. Hydrodynamique physique, EDP Sciences, 674 p.

Kassab, S.Z., Kandil, H.A., Warda, H.A., Ahmed, W.H., 2007. Experimental and analytical investigations of airlift pumps operating in three-phase flow. Chem. Eng. J. 131, 273-281.

Kassab, S.Z., Kandil, H.A., Warda, H.A., Ahmed, W.H., 2009. Air-lift pumps characteristics under two-phase flow conditions, Int. J. Heat Fluid Flow 30, 88-98.

Kawahara, A., Sadatomi, M., Matsuyama, F., Matsuura, H., Tominaga, M., Noguchi, M., 2009. Prediction of micro-bubble dissolution characteristics in water and seawater. Exp. Therm. Fluid. Sci. 33, 883-894.

Khalil, M.F., Elshorbagy, K.A., Kasab, S.Z., Fahmy, R.I., 1999. Effect of air injection method on the performance of an air lift pump, Int. J. Heat Fluid Flow 20, 598-604.

Loyless, J.C., Malone, R.F., 1998. Evaluation of air-lift pump capabilities for water delivery, aeration, and degasification for application to recirculating aquaculture systems. Aquacult. Eng. 18, 117-133.

Mamane, H., Colorni, A., Bar, I., Ori, I., Mozes, N., 2010. The use of an open channel, low pressure UV reactor for water treatment in low head recirculating aquaculture systems (LH-RAS). Aquacult. Eng. 42, 103-111. 
Moran, D., 2010b. Carbon dioxide degassing in fresh and saline water. II: Degassing performance of an air-lift. Aquacult. Eng. 43, 120-127.

Mozes, N., Haddas, I., Conijeski, D., Eshchar, M., 2004. The Low-Head Mega-Flow air driven Recirculating system - minimizing biological and operational risks. Proc. Aquacult. Eur. Conf., Barcelona, Spain, 598-599.

Nicklin, D.J., 1963. The air lift pump theory and optimization. Trans. Inst. Chem. Eng. 41, 29-39.

Parker, N.C., Suttle, M.A., 1987. Design of airlift pumps for water circulation and aeration in aquaculture. Aquacult. Eng. 6, 97-110.

Reinemann, D.J., 1987. A theoretical and experimental study of airlift pumping and aeration with reference to aquacultural applications. PhD dissertation, Cornell University, Ithaca, NY, $100 \mathrm{p}$.

Reinemann, D.J., Patrlange, J.Y., Timmons, M.B., 1990. Theory of small diameter air lift pump. Int. J. Multiphase Flow 16, 337-355.

Roque d'Orbcastel, E., Blancheton, J.P., Belaud, A., 2009. Water quality and rainbow trout performance in a Danish Model Farm recirculating system: Comparison with a flow through system. Aquacult. Eng. 40, 135-143.

Ruen-ngam, D., Wongsuchoto, P., Limpanuphap, A., Charinpanitkul, T., Pavasant, P., 2008. Influence of salinity on bubble size distribution and gas-liquid mass transfer in airlift contactors. Chem. Eng. J. 141, 222-232.

Wurts, W.A., McNeill, S.G., Overhults, D.G., 1994. Performance and design characteristics of airlift pumps for field applications. World Aquacult. 24, 51-54.

Yu, W., Wang, T.F., Liu, M., Wang, Z.W., 2008. Bubble Circulation Regimes in a Multi-Stage Internal-Loop Airlift Reactor. Chem. Eng. J. 142, 301-30. 